\title{
Distinctive morphological and molecular features of urothelial carcinoma with an inverted growth pattern
}

\author{
Francesca Sanguedolce ${ }^{1}$, Beppe Calò ${ }^{2}$, Marco Chirico ${ }^{3}$, Ugo Falagario ${ }^{3}$, Gian Maria Busetto ${ }^{3}$, Magda Zanellí, \\ Alessandra Bisagni ${ }^{4}$, Maurizio Zizzo ${ }^{5,6}$, Stefano Ascani ${ }^{7}$, Giuseppe Carrieri ${ }^{3}$, Luigi Cormio ${ }^{2}$ \\ ${ }^{1}$ Pathology Unit, University of Foggia, Foggia; \\ 2Urology Unit, University of Foggia, Bonomo Teaching Hospital, Foggia; \\ ${ }^{3}$ Urology and Renal Transplantation Unit, University of Foggia, Foggia; \\ ${ }^{4}$ Pathology Unit, Azienda USL-IRCCS di Reggio Emilia, Reggio Emilia; \\ ${ }^{5}$ Surgical Oncology Unit, Azienda USL-IRCCS di Reggio Emilia, Reggio Emilia; \\ ${ }^{6}$ Clinical and Experimental Medicine PhD Program, University of Modena and Reggio Emilia, Modena; \\ ${ }^{7}$ Pathology Unit, Azienda Ospedaliera S. Maria di Terni, University of Perugia, Terni, Italy
}

\begin{abstract}
Urothelial carcinoma with an inverted growth pattern (UC-IGP) is a peculiar entity within the spectrum of urothelial lesions. While efforts have been made over the last few decades to unravel its carcinogenesis and relationship with conventional urothelial carcinoma, the exact classification of inverted urothelial lesions is a matter of debate. The morphological features of UC-IGP pose several issues in differential diagnosis with other mostly benign lesions. Various techniques, including immunohistochemistry, UroVysion, and many molecular methods, have been employed to study the exact nature of this lesion. The aim of this review is to provide a comprehensive overview of the morphological and immunophenotypical aspects of UC-IGP. Moreover, we present and discuss the immunohistochemical and molecular markers involved in diagnosis and prognosis of UC-IGP lesions.
\end{abstract}

Key Words: Urothelial carcinoma; Inverted growth pattern; Immunohistochemistry; Molecular markers

Received: March 4, 2021 Revised: April 2, 2021 Accepted: April 20, 2021

Corresponding Author: Francesca Sanguedolce, MD, PhD, Pathology Unit, University Hospital 00.RR., University of Foggia, Viale Pinto 1, 71122 Foggia, Italy

Tel: +39-0881736315, Fax: +39-0881736334, E-mail: francesca.sanguedolce@unifg.it

The majority of urothelial neoplasms has an exophytic growth pattern, yet some show an inverted architecture [1-3]. A systematic approach to classification of inverted/endophytic urothelial lesions was made in 2012 by the International Consultation on Urologic Disease (ICUD). According to the existing World Health Organization (WHO)/International Society of Urologic Pathology (ISUP) system criteria for exophytic papillary neoplasms and on the basis of the presence and degree of atypia (including assessment of polarity), inverted neoplasms are graded as (1) inverted papilloma (IP), (2) inverted papillary urothelial neoplasm of low malignant potential (PUNLMP), (3) inverted papillary urothelial carcinoma (PUC), (4) low-grade, non-invasive, inverted PUC, (5) high-grade, non-invasive, inverted PUC, or (6) high-grade, invasive [4]. Due to the frequent occurrence of both exophytic and endophytic patterns in the same urothelial lesion, such terminology should apply only to malignant lesions with promi- nent inverted architecture [5]. However, this approach has been criticized for not considering other architectural and cytological features, namely presence of exophytic papillary structures, type of endophytic pattern (i.e., nests and trabeculae), number of cellular layers, and mitotic index [2,5].

Urothelial carcinoma (UC) with an inverted growth pattern (UC-IGP) is a malignant entity within this spectrum of lesions. Findings from the literature point out that these lesions carry peculiar histological and molecular features; however, issues in differential diagnosis can arise and affect the possibility of a proper diagnosis and subsequent adequate treatment. The aim of this review is to provide a comprehensive overview of the morphological and immunophenotypical aspects of UC-IGP. Moreover, we discuss the molecular evidence shedding light on the putative pathogenesis of this disease related to urothelial carcinogenesis. 


\section{MORPHOLOGICAL FEATURES}

According to the current WHO classification, papillary urothelial carcinoma with an inverted growth pattern (PUC-IGP) is a variant of non-invasive PUC and is staged as pTa [6]. Unlike conventional PUC, PUC-IGP shows an endophytic architectural pattern with branching and anastomosing cords of urothelium, some of which have an expansile appearance $[7,8]$. The stromalepithelial interface has a smooth profile with delicate vascular architecture. The cytological and architectural features lead similar grading as for conventional UCs, namely low-grade (LG) and high-grade (HG) [8], featuring nuclear atypia, architectural abnormality, and mitotic activity $[9,10]$. Such changes are present at the surface of the lesion in most cases, further supporting a diagnosis of UC. An exophytic papillary element has been reported in association with the inverted component $[1,11]$, as well as a pseudoexophytic pattern resulting from artifactual fragmentation of the specimen.

The presence of prominent endophytic growth can be misdiagnosed as a pushing border of invasion, yet occasional true lamina propria invasion is supported by a stromal reaction $[1,5,7,12]$ and/or neoplastic cords interweaving with fibers of muscularis mucosae $[1,13]$. Features such as irregularity of the endophytic nest profile, architectural complexity, and occurrence of single-cell invasion can be useful and should raise suspicion of an invasive lesion [14]. Transurethral resection (TUR)-related artifacts, namely tangential sectioning, cauterization, and crush effect, represent further issues in assessing stromal and/or muscular invasion $[1,13]$.

In a recent large series of invasive HG-UC arising in a background of UC-IGP from various sites, Gutierrez et al. [15] reported on bladder tumors presenting at earlier stages $(81 \% \mathrm{pT} 1)$ than those involving the upper urinary tract $(80 \%$ and $43 \% \geq \mathrm{pT} 2$ in the renal pelvis and ureter, respectively). UC in situ and variant histology were described in approximately $40 \%$ and $20 \%$ of all cases, respectively [15], the latter being associated with a more aggressive clinical behavior. Conversely, a previous study on 81 non-invasive LG-UC of the bladder, including eight UC-IGP, reported a lower recurrence risk in the inverted group [16]. A first attempt to classify PUC-IGP was conducted in 1997 by Amin et al. [13], who described two main histologic patterns featuring interanastomosing cords and trabeculae (IP-like pattern) and broad bulbous borders (broad-front pattern), respectively $[13,17]$.

LG-PUC-IGP shows mild nuclear atypia in terms of irregular chromatin distribution, enlarged irregular nucleoli, expansile growth with inverted nests and clusters, and increased mitoses $[8,18]$. HG-PUC-IGP has predominant inverted growth with higher architectural disorder in terms of marked loss of polarity with respect to the basement membrane [4], along with significant nuclear pleomorphism and increased mitotic activity with occasional atypical figures. However, many reported cases of "atypical inverted urothelial papilloma" are described with an exophytic papillary component and significant atypia and/or mitoses, which would best be considered UC with inverted growth $[5,19]$.

\section{IMMUNOHISTOCHEMICAL MARKERS}

\section{CD44}

CD44 is a stem cell surface marker typically present in the basal layer of normal urothelium; however, UC in situ and the luminal subtype of invasive UC lack CD44 expression [8]. In their recent study on UC-IGPs of various grade, Bang et al. [2] described CD44 expression in two-thirds of their LG cases, while all $\mathrm{HG}$ tumors were negative. Further studies are needed to assess the potential of $\mathrm{CD} 44$ as a diagnostic and prognostic marker in this setting.

\section{Cytokeratin 20}

Cytokeratin 20 (CK20) is a low-molecular weight cytokeratin with diagnostic and prognostic potential in urothelial lesions [20]. CK20 is expressed commonly by superficial cells only in the normal urothelium; therefore, it is a marker of urothelial maturation and differentiation [5]. The immunohistochemical expression of CK20 is of diagnostic value in differentiating IP from UC-IGP [1-3] (Table 1). Moreover, Sun et al. [3] reported that combining Ki67 and CK20 assessment by immunohistochemistry with UroVysion fluorescence in situ hybridization (FISH) showed sensitivity and specificity as high as $89.5 \%$ and $100 \%$, respectively.

\section{Cyclin D1}

Cyclin D1 is a key regulator of the cell cycle, and its alterations have been implicated in bladder carcinogenesis [21]. Cyclin D1 status has been studied as a prognostic marker in nonmuscle invasive bladder cancer (NMIBC), with conflicting results [21] (Table 1). The LG-IP-like UC reported by Sudo et al. [22] showed cytoplasmic expression of cyclin D1 along with other immunohistochemical markers. Interestingly, Bang et al. [2] found that 28 of $60(47 \%)$ inverted urothelial neoplasms were positive for nuclear cyclin D1, in the absence of significant difference in stain- 
Table 1. Expression of selected immunohistochemical markers in UC-IGP

\begin{tabular}{|c|c|c|c|c|c|c|c|c|c|c|c|c|c|}
\hline \multirow{2}{*}{ Study } & \multirow{2}{*}{ Site (No.) } & \multicolumn{2}{|c|}{ CK20 } & \multicolumn{2}{|c|}{ Cyclin D1 } & \multicolumn{2}{|c|}{ HER2 } & \multicolumn{2}{|l|}{ Ki67 } & \multicolumn{2}{|c|}{ p16 } & \multicolumn{2}{|l|}{ p53 } \\
\hline & & LG & $H G$ & LG & $H G$ & LG & $H G$ & LG & $H G$ & LG & $H G$ & LG & $H G$ \\
\hline Cheon et al. [29] & Bladder (2) & - & - & - & - & \multicolumn{2}{|c|}{$2 / 2(100)$} & - & - & - & - & - & - \\
\hline Eiber et al. [31] & Bladder (22) & \multicolumn{2}{|c|}{$9 / 22(41)$} & - & - & - & - & \multicolumn{2}{|c|}{ 18/22 (82) } & - & - & \multicolumn{2}{|c|}{ 6/22 (27) } \\
\hline Jones et al. [1] & Bladder (29) & \multicolumn{2}{|c|}{ 17/29 (59) } & - & - & - & - & \multicolumn{2}{|c|}{ 19/29 (66) } & - & - & \multicolumn{2}{|c|}{$17 / 29$ (59) } \\
\hline Terada [32] & Bladder (3) & - & - & - & & - & - & \multicolumn{2}{|c|}{$3 / 3(100)$} & - & - & \multicolumn{2}{|c|}{$3 / 3(100)$} \\
\hline Ehsani et al. [30] & Renal pelvis (23) & - & - & - & & \multicolumn{2}{|c|}{ 15/23 (65) } & - & - & - & - & - & - \\
\hline McDaniel et al. [18] & $\begin{array}{l}\text { Bladder (8), renal } \\
\text { pelvis (1) }\end{array}$ & - & - & - & & - & - & - & - & $3 / 5(60)$ & $2 / 4(50)$ & - & - \\
\hline Sun et al. [3] & - & 14/38 (36.8) & - & 28/38 (73.7) & - & - & - & $18 / 38(47.4)$ & - & - & - & $16 / 38(42.1)$ & - \\
\hline Bang et al. [2] & Bladder (19) & $4 / 15(27)$ & $3 / 4(75)$ & $7 / 15(47)$ & $2 / 4(50)$ & $1 / 15(7)$ & $1 / 4(25)$ & $1 / 15(7)$ & $2 / 4(50)$ & $3 / 15(20)$ & 3/4 (75) & $4 / 15(27)$ & $3 / 4(75)$ \\
\hline
\end{tabular}

Values are presented as number (\%).

UC-IGP, urothelial carcinoma with an inverted growth pattern; CK20, cytokeratin 20; HER2, human epidermal growth factor receptor 2; HG, high-grade; LG, low-grade.

ing levels between benign and malignant lesions. Accordingly, cyclin D1 nuclear expression was higher in LG-UC-IGP than in IP (73.7\% vs. $69.4 \%$, respectively) in the study by Sun et al. [3], but the difference did not achieve statistical significance $(\mathrm{p}=.798)$. Based on these findings, cyclin D1 seems not to be helpful in differential diagnosis of benign and malignant inverted lesions.

\section{Human epidermal growth factor receptor 2}

Human epidermal growth factor receptor 2 (HER2) is a tyrosine kinase receptor with oncogenic potential that is overexpressed in 5\%-10\% of UC, including nonmuscle invasive lesions [23-25]. HER2 expression has prognostic and therapeutic implications, since anti-HER 2 targeted drugs are the standard-of-care for patients with HER2 + breast and gastroesophageal cancer [26,27]. However, analytical and pre-analytical issues can affect the reliability of HER 2 assessment through current methods, especially with TUR specimens [28]. Cheon et al. [29] found moderate to strong HER2 overexpression (defined as distinct membrane staining) in two malignant bladder lesions with inverted pattern compared to five IP, which were negative for HER2. Similarly, significantly higher levels of HER2 expression ( $\mathrm{p}=.0465)$ were described in UC-IGP compared with IP and PUNLMP-IGP using a $10 \%$ cutoff in a recent study by Bang et al. [2]. In addition, Ehsani and Osunkoya [30] reported a HER2 positivity rate (defined as strong complete membrane staining in $>30 \%$ cells) as high as $74 \%$ in their series of 46 renal pelvis UC cases; of them, 23 UC-IGP showed HER2 overexpression in $65 \%$ of cases, mostly HG-UC. Based on these results (Table 1), HER2 might be useful in differentiating malignant from benign lesions with an inverted growth pattern.

\section{Ki67}

The proliferative index assessed by scoring Ki67 nuclear an- tigen has been studied extensively in both NMIBC and muscle invasive bladder cancer (MIBC) [21] and in inverted lesions as well. Overall, it has been reported as diffusely expressed in UCIGP $[1,2,22,31,32]$ with significantly higher level compared to that in benign inverted lesions [1-3,31]. Consistent with these results, assessment of proliferative activity using proliferating cell nuclear antigen antibody and AgNOR silver colloid staining yielded higher expression rates of both markers in malignant inverted lesions compared to IPs [29]. Eiber et al. [31] suggest that a combined assessment of fibroblast growth factor receptor 3 (FGFR3) mutation status and Ki67 proliferation index can yield a specificity as high as $>90 \%$ in differentiating UC-IGP from IP within a consistent histological setting, with a Ki67 labeling index $<5 \%$ and wild-type FGFR3 being associated with a benign lesion. It has been suggested that the rate of Ki67 positive cells tends toward constant growth and expansion at the center of the lesion as grade increases $[1,33]$; therefore, this marker might be an adjunct in disease grading (Table 1 ).

p16

In bladder cancer, p16 has been analyzed either in association with other cell cycle proteins as a prognostic/predictive factor or as an indirect marker of human papillomavirus-induced carcinogenesis [21]. The two studies assessing p16 expression in UCIGP yielded overlapping results, with higher expression of p16 in malignant compared to benign lesions, without statistical significance (Table 1). Furthermore, in both studies, a more diffuse staining pattern was described in HG-UC versus LG-UC $[2,18]$.

p53

The gene encoding tumor suppressor protein $\mathrm{p} 53$ is the most common target for mutations in human cancer, and alterations of p53 at a molecular level are found in early bladder carcinogenesis 
events. p53 status seems to have a prognostic role in both NMIBC and MIBC, yet with contradictory results [21,34,35]. Although usually overexpressed in UC-IGP [22,32], no significant difference in $\mathrm{p} 53$ expression between benign and malignant inverted lesions was reported using different cutoffs $(10 \%-50 \%)$ [2,31]. Conversely, Sun et al. [3] reported significantly higher p53 staining (cutoff, 10\%) in a series of LG-UC-IGP compared to IP ( $\mathrm{p}=.001)$. Similarly, Jones et al. [1] described a steady increase in p53 expression in UC-IGP versus IP (59\% vs. $7 \%$ ) using a $1 \%$ cutoff, suggesting that p 53 should be part of a multi-marker panel (along with Ki67 and CK20) to distinguish benign from malignant inverted lesions. Interestingly, there were no statistically significant differences in $\mathrm{p} 53$ protein staining between IPs in patients with and without a history of UC [36] and between IPs with and without atypia [37] in two previous studies (Table 1). The use of different cutoffs can impair the reproducibility of immunohistochemical results among studies.

\section{MOLECULAR FEATURES}

\section{RAS genes}

HRAS and KRAS are prototype RAS oncoproteins that have been shown to infrequently incur mutations in conventional UC $[21,35]$. Conversely, HRAS mutations have been reported in inverted tumors [18], along with mutations in other members of the RAS pathway, namely mutations encoding the KRAS G12R and BRAF G469A mutants in LG-UC-IGP and HG-UC-IGP cases, respectively [18]. Moreover, an oncogenic HRAS or KRAS missense mutation was present in nearly all cases of IP and urothelial papilloma according to a recent series [38-40], compared to two of 25 UC-IGP cases (8\%). In both cases, further oncogenic mutations in chromatin-modifying genes and/or cell cycle regulators were present. Based on such findings, it has been suggested that an altered RAS pathway supplies the growth and/or progression of inverted urothelial lesions [18].

\section{Loss of heterozygosity}

Chromosomal aberrations, namely changes of copy numbers of various genetic regions, can occur at several points along the UC pathway that can be detected by cytogenetic studies, including loss of heterozygosity (LOH) analysis [21]. Sung et al. [41] found a very low incidence of $\mathrm{LOH}$ at genetic loci, which are frequently lost in both UCs and PNULMPs, by examining four polymorphic microsatellite markers [42] in their series of 39 IPs. LOH analysis performed by Eiber et al. [31] on 62 IPs and 23 UC-IGPs using microsatellite markers at chromosomal loci 9p21, 9q, and 17p13.1 identified statistically significant differences in 9q LOH (13.2\% of IPs vs. 36.4\% of UC-IGPs, p=.03).

\section{Telomere shortening}

Telomeres are repetitive DNA sequences that protect chromosome ends. A process known as telomere shortening (TS) occurs with every iteration of DNA replication and cell division. Telomerase is a DNA polymerase that counteracts TS by repairing chromosome ends, and the expression of its catalytic subunit telomerase reverse transcriptase (TERT) is correlated with telomerase activity [35]. TS and telomerase activity are involved in cancer development and progression at different sites, including the bladder [43]. Williamson et al. [44] reported that relative telomere length, as assessed by FISH analysis with a telomere-specific peptide nucleic acid probe, was significantly reduced in UCIGP compared to IP ( $\mathrm{p}$.001). Interestingly, analysis of relative telomere signal intensity in normal urothelium, non-neoplastic lesions (cystitis glandularis), and IP yielded similar results [44]. Based on these results, the authors argued that IPs do not have premalignant potential, and that benign and malignant inverted lesions develop through different carcinogenetic pathways despite their morphological similarity.

TERT promoter mutations have been detected infrequently in IPs $[39,45,46]$. Similarly, Cheng et al. [10] identified a significantly lower rate of TERT mutations in IP compared with UCIGP (15\% vs. 58\%, p=.003). Interestingly, the same C228T mutation was found in inverted lesions as well as in the majority of conventional UC, suggesting that a subset of IP might share a molecular pathway of carcinogenesis with UC-IGP and conventional UC [47]. Such findings suggest the use of TERT mutation analysis in the differential diagnosis of benign and malignant lesions $[38,40,47-49]$.

\section{UroVysion}

UroVysion is a multicolor FISH-based urine assay with higher sensitivity than urine cytology in the setting of UC screening and follow-up [21]. This assay assesses amplification of chromosomes 3, 7, and 17 along with deletion of $9 \mathrm{p} 21$. Such alterations have been detected in up to $79 \%$ of UC-IGPs through different studies $[1,5,7,33]$. In their multimethod study on a series of 15 IPs and 29 UC-IGPs, Jones at al. [1] yielded normal results for all cases of IP, while UC-IGP demonstrated chromosomal abnormalities typical of conventional UC, including gains of chromosomes 3 and 7. Accordingly, UroVysion positivity, defined as a gain of at least two of chromosomes 3,7 , or 17 or a homozygous loss of 9p21, yielded increased sensitivity and specificity rates 
compared to the immunohistochemical markers Ki67 and CK20 [3], and even higher accuracy was accomplished by a combination of the three tests, further highlighting the role of UroVysion in distinction between IP and UC-IGP.

\section{Microsatellite instability}

Microsatellite instability (MSI) resulting from errors in DNA replication is a distinctive feature of several tumors, including BC, where it has been reported to be associated with increased grade and stage [21] and to have a predictive role, especially in NMIBC [25]. MSI status can be assessed either directly by microsatellite analysis, a PCR-based technique, or indirectly by assessing the MSI factors MutL homologue 1 (MLH1), MutS homologue 2 (MSH2), and MutS homologue 6 (MSH6).

A frequent association between MSI positive status and inverted growth pattern in tumors of the upper urinary tract has been described [50,51], mostly highlighted by MSH2 and/or MSH6 protein loss. Eiber et al. [31] investigated MSI in their series of IPs and UC-IGPs through both microsatellite analysis and MLH1, MSH2, and MSH6 immunostaining; however, they failed to find a significant correlation between MSI status and diagnosis [31]. Based on these findings, they argued that microsatellite unstable inverted tumors of the upper urinary tract represent a distinct subgroup of inverted urothelial tumors.

\section{FGFR3}

FGFR3 is a member of the family of fibroblast growth factor tyrosine kinase receptors that is involved in urothelial carcinogenesis through a papillary pathway associated with low cellular grade and lack of invasion [52]. Alterations of the FGFR3 gene have been described in UC-IGP, namely activating mutations encoding S249C, R248C, and G370C [18]. Since such alterations have been detected in both LG-UC-IGP and HG-UC-IGP, a possible explanation could be the non-invasive nature of inverted lesions overall, despite their grade of differentiation [18].

\section{Distinct molecular alterations in inverted urothelial lesions}

Evidence from molecular genetic studies has shown that IPs have additional distinct molecular features compared to their malignant counterparts, such as low tumor mutational burden, mutations in the mitogen-activated protein kinase/ERK pathway, along with a lack of the prevalent $A P O B E C$ mutation signature $[1,7,31,36,38-41]$. On the other hand, both conventional UC and UC-IGP carry overlapping genetic alterations [53], namely mutations in FGFR3, TP53, CDKN1A, PIK3CA, FBXW7, ERBB2, and NOTCH1 [18,40]. Interestingly, the specific point mutations at FBXW7 R505, ERBB2 V842, and NOTCH1 R1594 have not been reported in conventional urothelial cancers [54]. UC-IGP arising in the upper urinary tract has been described in association with hereditary non-polyposis colorectal cancer syndrome/Lynch syndrome, with DNA mismatch repair gene abnormalities and MSI [55], and the latter are more frequent in tumors of the renal pelvis and ureter than in bladder primaries and can be used as prognostic markers [25].

\section{Differential diagnosis}

Several authors have highlighted the high potential for misinterpretation of UC-IGP as IP due to overlapping morphological features [1,7,11-15,22,44]; however, a combination of morphologic, immunohistochemical, and molecular genetic assessments can be helpful in achieving a correct diagnosis [1]. This task is particularly challenging when the cystoscopy-obtained biopsy tissue is limited, extensively fragmented, heavily inflamed, and/or obscured by crush or cautery artifacts [15]. IPs are relatively less frequent than conventional urothelial benign papillary neoplasms, can be encountered anywhere throughout the urinary tract, and do not undergo malignant transformation [56].

Amin et al. [13] analyzed 18 UC-IGPs and established several morphologic criteria to distinguish them from IPs. UC-IGP tends to have an exophytic papillary surface, thick irregular cords or trabeculae, grade-dependent cytological atypia, and decrease to lack of maturation, spindling, or peripheral palisading [2,3,5,10,18,32]. Cytologic atypia presents in the form of nuclear pleomorphism, irregular chromatic structure, and/or enlarged uneven nucleoli [57]. Furthermore, UC-IGPs tend to have greater mitotic activity above the basal layer with occasionally atypical mitotic figures $[3,57]$. The presence of UC in situ in the surface urothelium is a further hint to diagnosis of UC-IGP [7].

Conversely, IPs have a smooth, dome-shaped surface due to the endophytic growth of uniform cords and trabeculae, usually lack an exophytic element, are more circumscribed, feature palisading at the periphery and spindling or streaming in the center of the trabeculae, and cytologic atypia is weak to absent [3,31]. It is clear that IPs lack stromal invasion; however, IPs with foamy/ clear or vacuolated cytoplasm have been described occasionally [19]. At cystoscopy, IP usually appears as a single peduncle mass with smooth surface, while UC-IGP presents as wide-based, cauliflower-like multiple masses with an uneven surface [5] (Fig. 1).

It has been suggested that most lesions diagnosed in the past as IP with concurrent UC were actually UC-IGPs [58], and some IPs were labeled as LG-UC-IGPs [59], resulting in confusion regarding the actual incidence of each disease. Moreover, a cate- 


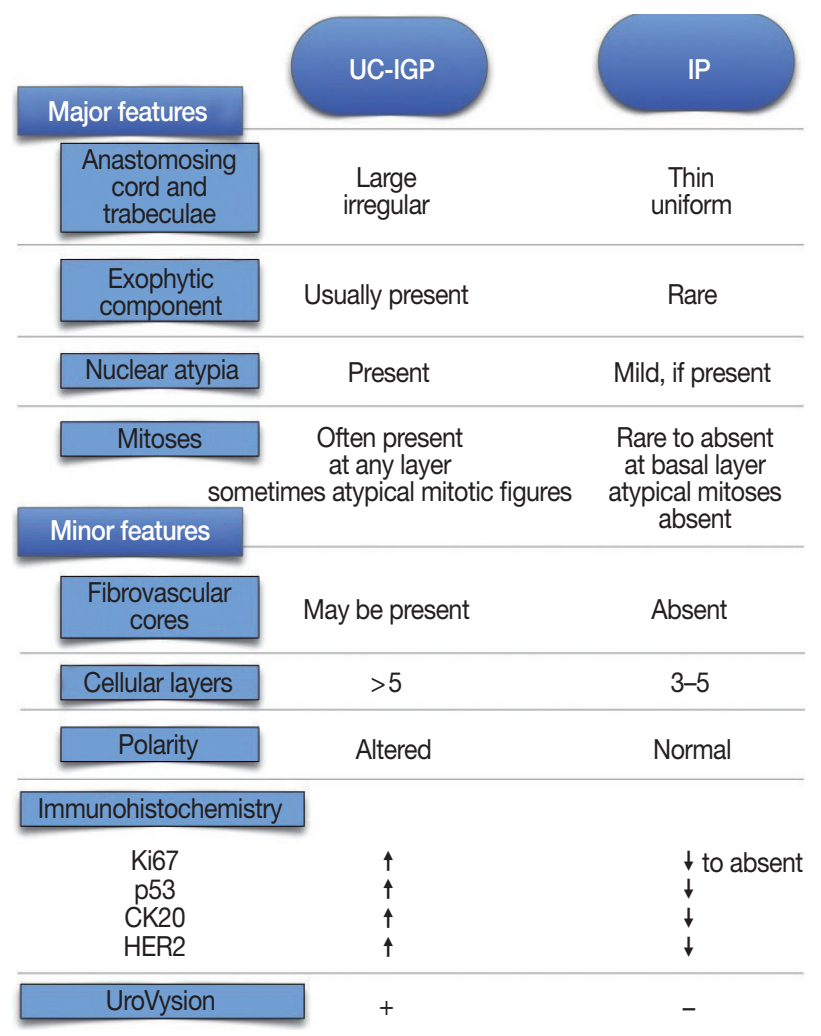

Fig. 1. Summary of the main morphological, immunohistochemical, and molecular differential features of urothelial carcinoma with an inverted growth pattern (UC-IGP) and inverted papilloma (IP). CK20, cytokeratin 20; HER2, human epidermal growth factor receptor 2.

gory of "IP with atypia" or "atypical IP" was introduced by some authors, referring to a subset of IP with malignant potential [36,37]. Compared to UC-IGP, IP with atypia has lower mitotic index and proliferative activity. Interestingly, Brimo et al. reported on a series of 12 UC-IGPs encompassing areas within the tumor whose morphological features were identical to those of IP in each case [17]. Immunohistochemically, higher rates of p53 and CK20 expression and increased $\mathrm{Ki} 67$ proliferative index were seen in UCIGP compared to IP $[1,7,14,44]$. Sun et al. [3] described higher Ki67 and CK20 expression in LG-UC-IGP than IP. Interestingly, Broussard et al. [37] found a higher incidence of Ki67 and p53 in IPs with atypia compared to conventional IPs. Moreover, 24 of 38 (63.2\%) LG-UC-IGP cases were positive for UroVysion FISH, whereas all IPs showed no gains of chromosomes 3, 7, or 17 and absence of 9p21 loss, suggesting that IP arises from pathogenetic mechanisms that differ from those that produce UC (Fig. 1).

As a lesion with an endophytic growth pattern, a large-nested variant of invasive UC enters the differential diagnosis with UCIGP. However, involvement of the detrusor muscle as well as the high variability of size and shape, irregular profile, and infiltra- tive architecture of large-nested UC allow distinction between the two [60].

\section{CONCLUSION}

In conclusion, UC-IGP and IP are distinct entities with peculiar biologic behaviors and clinical outcomes that can be difficult to distinguish due to their morphological commonalities. However, misdiagnosis should be avoided since IP is a benign disease, while UC-IGP can warrant further treatment or surveillance depending on grade $[2,7,56]$. Data from the literature assess the role of ancillary techniques, namely immunohistochemistry and FISH, in supporting a proper diagnosis [3]. However, studies on large case series are warranted to further elucidate the molecular mechanisms and diagnostic and prognostic markers of UC-IGP.

\section{Ethics Statement \\ Not applicable.}

\section{Availability of Data and Material}

Data sharing not applicable to this article as no datasets were generated or analyzed during the study.

\section{Code Availability}

Not applicable.

\section{ORCID}

Francesca Sanguedolce

Beppe Calò

Marco Chirico

Ugo Falagario

Gian Maria Busetto

Magda Zanelli

Alessandra Bisagni

Maurizio Zizzo

Stefano Ascani

Giuseppe Carrieri

Luigi Cormio

https://orcid.org/0000-0001-7459-3521 https://orcid.org/0000-0001-9285-9426 https://orcid.org/0000-0002-0637-1481 https://orcid.org/0000-0002-1152-3005 https://orcid.org/0000-0002-7291-0316 https://orcid.org/0000-0002-8733-9933 https://orcid.org/0000-0001-8484-7871 https://orcid.org/0000-0001-9841-7856 https://orcid.org/0000-0002-4516-9040 https://orcid.org/0000-0002-6609-6434 https://orcid.org/0000-0002-1126-5368

\section{Author Contributions}

Conceptualization: FS. Project administration: FS, MZ (Magda Zanelli), LC. Supervision: GC, LC. Writing_original draft: FS, BC, MC, UF, GMB, MZ (Magda Zanelli), AB, MZ (Maurizio Zizzo), SA. Writing-review \& editing: FS, SA, GC, LC. Approval of final manuscript: all authors.

\section{Conflicts of Interest}

The authors declare that they have no potential conflicts of interest.

\section{Funding Statement}

No funding to declare.

\section{References}

1. Jones TD, Zhang S, Lopez-Beltran A, et al. Urothelial carcinoma with an inverted growth pattern can be distinguished from inverted 
papilloma by fluorescence in situ hybridization, immunohistochemistry, and morphologic analysis. Am J Surg Pathol 2007; 31: 1861-7.

2. Bang H, Park H, Park S, et al. Clinicopathologic study of 60 cases of urothelial neoplasms with inverted growth patterns: reclassification by international consultation on urologic disease (ICUD) recommendations. Ann Diagn Pathol 2020; 44: 151433.

3. Sun JJ, Wu Y, Lu YM, et al. Immunohistochemistry and fluorescence in situ hybridization can inform the differential diagnosis of low-grade noninvasive urothelial carcinoma with an inverted growth pattern and inverted urothelial papilloma. PLoS One 2015; 10: e0133530.

4. Amin MB, Smith SC, Reuter VE, et al. Update for the practicing pathologist: The International Consultation on Urologic Disease-European association of urology consultation on bladder cancer. Mod Pathol 2015; 28: 612-30.

5. Guo A, Liu A, Teng X. The pathology of urinary bladder lesions with an inverted growth pattern. Chin J Cancer Res 2016; 28: 107-21.

6. Lopez-Beltran A, Cheng L. Stage T1 bladder cancer: diagnostic criteria and pitfalls. Pathology 2021; 53: 67-85.

7. Hodges KB, Lopez-Beltran A, Maclennan GT, Montironi R, Cheng L. Urothelial lesions with inverted growth patterns: histogenesis, molecular genetic findings, differential diagnosis and clinical management. BJU Int 2011; 107: 532-7.

8. Moch H, Humphrey PA, Ulbright TM, Reuter VE. WHO classification of tumours of the urinary system and male genital organs. 4th ed. Lyon: IARC, 2016; 100-2.

9. Lopez-Beltran A, Montironi R, Cheng L. Pathology of the urinary bladder: an algorithmic approach. Cambridge: Cambridge University Press, 2016; 1-163.

10. Cheng L, MacLennan GT, Bostwick DG. Urologic surgical pathology. 4th ed. Philadelphia: Elsevier, 2020; 230-63.

11. Terai A, Tamaki M, Hayashida H, Tomoyosh T, Takeuchi H, Yoshida O. Bulky transitional cell carcinoma of bladder with inverted proliferation. Int J Urol 1996; 3: 316-9.

12. Lopez-Beltran A, Cheng L. Histologic variants of urothelial carcinoma: differential diagnosis and clinical implications. Hum Pathol 2006; 37: 1371-88.

13. Amin MB, Gomez JA, Young RH. Urothelial transitional cell carcinoma with endophytic growth patterns: a discussion of patterns of invasion and problems associated with assessment of invasion in 18 cases. Am J Surg Pathol 1997; 21: 1057-68.

14. Montironi R, Cheng L, Lopez-Beltran A, et al. Inverted (endophytic) noninvasive lesions and neoplasms of the urothelium: the Cinderella group has yet to be fully exploited. Eur Urol 2011; 59: 225-30.

15. Gutierrez CM, Alemozaffar M, Osunkoya AO. Invasive high-grade urothelial carcinoma of the bladder, renal pelvis, ureter, and prostatic urethra arising in a background of urothelial carcinoma with an inverted growth pattern: a contemporary clinicopathological analysis of 91 cases. Hum Pathol 2019; 92: 18-24.

16. Arslankoz S, Kulac I, Ertoy Baydar D. The influence of inverted growth pattern on recurrence for patients with non-invasive low grade papillary urothelial carcinoma of bladder. Balkan Med J 2017; 34: 464-8.

17. Brimo F, Dauphin-Pierre S, Aprikian A, et al. Inverted urothelial carcinoma: a series of 12 cases with a wide morphologic spectrum overlapping with the large nested variant. Hum Pathol 2015; 46: 1506-13.

18. McDaniel AS, Zhai Y, Cho KR, et al. HRAS mutations are frequent in inverted urothelial neoplasms. Hum Pathol 2014; 45: 1957-65.
19. Fine SW, Epstein JI. Inverted urothelial papillomas with foamy or vacuolated cytoplasm. Hum Pathol 2006; 37: 1577-82.

20. Sanguedolce F, Russo D, Calo B, Cindolo L, Carrieri G, Cormio L. Diagnostic and prognostic roles of CK20 in the pathology of urothelial lesions: a systematic review. Pathol Res Pract 2019; 215: 152413.

21. Sanguedolce F, Bufo P, Carrieri G, Cormio L. Predictive markers in bladder cancer: do we have molecular markers ready for clinical use? Crit Rev Clin Lab Sci 2014; 51: 291-304.

22. Sudo T, Irie A, Ishii D, Satoh E, Mitomi H, Baba S. Histopathologic and biologic characteristics of a transitional cell carcinoma with inverted papilloma-like endophytic growth pattern. Urology 2003; 61: 837.

23. Lae M, Couturier J, Oudard S, Radvanyi F, Beuzeboc P, Vieillefond A. Assessing HER2 gene amplification as a potential target for therapy in invasive urothelial bladder cancer with a standardized methodology: results in 1005 patients. Ann Oncol 2010; 21: 815-9.

24. Cormio L, Sanguedolce F, Cormio A, et al. Human epidermal growth factor receptor 2 expression is more important than Bacillus Calmette Guerin treatment in predicting the outcome of T1G3 bladder cancer. Oncotarget 2017; 8: 25433-41.

25. Sanguedolce F, Cormio A, Massenio P, et al. Altered expression of HER-2 and the mismatch repair genes MLH1 and MSH2 predicts the outcome of T1 high-grade bladder cancer. J Cancer Res Clin Oncol 2018; 144: 637-44.

26. Sanguedolce F, Russo D, Mancini V, et al. Prognostic and therapeutic role of HER2 expression in micropapillary carcinoma of the bladder. Mol Clin Oncol 2019; 10: 205-13.

27. Oh DY, Bang YJ. HER2-targeted therapies-a role beyond breast cancer. Nat Rev Clin Oncol 2020; 17: 33-48.

28. Sanguedolce F, Russo D, Mancini V, et al. Human epidermal growth factor receptor 2 in non-muscle invasive bladder cancer: issues in assessment methods and its role as prognostic/predictive marker and putative therapeutic target: a comprehensive review. Urol Int 2019; 102: 249-61.

29. Cheon J, Kim HK, Kim JJ, Yoon DK, Koh SK, Kim IS. Malignant inverted papilloma of the urinary bladder: the histopathological aspect of malignant potential of inverted papilloma. J Korean Med Sci 1995; 10: 103-10.

30. Ehsani L, Osunkoya AO. Human epidermal growth factor receptor 2 expression in urothelial carcinoma of the renal pelvis: correlation with clinicopathologic parameters. Int J Clin Exp Pathol 2014; 7: 2544-50.

31. Eiber M, van Oers JM, Zwarthoff EC, et al. Low frequency of molecular changes and tumor recurrence in inverted papillomas of the urinary tract. Am J Surg Pathol 2007; 31: 938-46.

32. Terada T. Inverted variant of urothelial carcinoma of the urinary bladder: a report of three cases and a proposal for a new clinicopathologic entity. Int J Clin Exp Pathol 2013; 6: 766-70.

33. Urakami S, Igawa M, Shirakawa H, Shiina H, Ishibe T. Inverted papilloma of the urinary bladder: a case evaluated for malignant potential. Int Urol Nephrol 1997; 29: 181-7.

34. Cormio L, Tolve I, Annese P, et al. Altered p53 and pRb expression is predictive of response to $\mathrm{BCG}$ treatment in T1G3 bladder cancer. Anticancer Res 2009; 29: 4201-4.

35. Sanguedolce F, Cormio A, Bufo P, Carrieri G, Cormio L. Molecular markers in bladder cancer: Novel research frontiers. Crit Rev Clin Lab Sci 2015; 52: 242-55.

36. Cheville JC, Wu K, Sebo TJ, et al. Inverted urothelial papilloma: is 
ploidy, MIB-1 proliferative activity, or $\mathrm{p} 53$ protein accumulation predictive of urothelial carcinoma? Cancer 2000; 88: 632-6.

37. Broussard JN, Tan PH, Epstein JI. Atypia in inverted urothelial papillomas: pathology and prognostic significance. Hum Pathol 2004; 35: 1499-504.

38. Akgul M, MacLennan GT, Cheng L. Distinct mutational landscape of inverted urothelial papilloma. J Pathol 2019; 249: 3-5.

39. Isharwal S, Hu W, Sarungbam J, et al. Genomic landscape of inverted urothelial papilloma and urothelial papilloma of the bladder. J Pathol 2019; 248: 260-5.

40. Almassi N, Pietzak EJ, Sarungbam J, et al. Inverted urothelial papilloma and urothelial carcinoma with inverted growth are histologically and molecularly distinct entities. J Pathol 2020; 250: 464-5.

41. Sung MT, Eble JN, Wang M, Tan PH, Lopez-Beltran A, Cheng L. Inverted papilloma of the urinary bladder: a molecular genetic appraisal. Mod Pathol 2006; 19: 1289-94.

42. Junker K, Boerner D, Schulze W, Utting M, Schubert J, Werner W. Analysis of genetic alterations in normal bladder urothelium. Urology 2003; 62: 1134-8.

43. Zhu X, Han W, Xue W, et al. The association between telomere length and cancer risk in population studies. Sci Rep 2016; 6: 22243.

44. Williamson SR, Zhang S, Lopez-Beltran A, Montironi R, Wang M, Cheng L. Telomere shortening distinguishes inverted urothelial neoplasms. Histopathology 2013; 62: 595-601.

45. Wang CC, Huang CY, Jhuang YL, Chen CC, Jeng YM. Biological significance of TERT promoter mutation in papillary urothelial neoplasm of low malignant potential. Histopathology 2018; 72: 795-803.

46. Kurtis B, Zhuge J, Ojaimi C, et al. Recurrent TERT promoter mutations in urothelial carcinoma and potential clinical applications. Ann Diagn Pathol 2016; 21: 7-11.

47. Cheng L, Davidson DD, Wang M, et al. Telomerase reverse transcriptase (TERT) promoter mutation analysis of benign, malignant and reactive urothelial lesions reveals a subpopulation of inverted papilloma with immortalizing genetic change. Histopathology 2016; 69: 107-13.

48. Warrick JI, Knowles MA, Yves A, et al. Report From the International Society of Urological Pathology (ISUP) Consultation Conference on Molecular Pathology of Urogenital Cancers. II. Molecular pathol- ogy of bladder cancer: progress and challenges. Am J Surg Pathol 2020; 44: e30-46.

49. Cheng L, Montironi R, Lopez-Beltran A. TERT promoter mutations occur frequently in urothelial papilloma and papillary urothelial neoplasm of low malignant potential. Eur Urol 2017; 71: 497-8.

50. Catto JW, Azzouzi AR, Amira N, et al. Distinct patterns of microsatellite instability are seen in tumours of the urinary tract. Oncogene 2003; 22: 8699-706.

51. Harper HL, McKenney JK, Heald B, et al. Upper tract urothelial carcinomas: frequency of association with mismatch repair protein loss and lynch syndrome. Mod Pathol 2017; 30: 146-56.

52. Ertl IE, Shariat SF, Mostafaei H, Ilijazi D, Loriot Y. Fibroblast growth factor receptors across urothelial carcinoma landscape. Curr Opin Urol 2020; 30: 557-65.

53. Pietzak EJ, Bagrodia A, Cha EK, et al. Next-generation sequencing of nonmuscle invasive bladder cancer reveals potential biomarkers and rational therapeutic targets. Eur Urol 2017; 72: 952-9.

54. Cancer Genome Atlas Research Network. Comprehensive molecular characterization of urothelial bladder carcinoma. Nature 2014; 507: 315-22.

55. Hartmann A, Dietmaier W, Hofstadter F, Burgart LJ, Cheville JC, Blaszyk $\mathrm{H}$. Urothelial carcinoma of the upper urinary tract: inverted growth pattern is predictive of microsatellite instability. Hum Pathol 2003; 34: 222-7.

56. Sweeney MK, Rais-Bahrami S, Gordetsky J. Inverted urothelial papilloma: a review of diagnostic pitfalls and clinical management. Can Urol Assoc J 2017; 11: 66-9.

57. Raspollini MR, Lopez-Beltran A. Uropathology. Cham: Springer, 2020; 158-61.

58. Epstein JI, Reuter VE, Amin MB. Biopsy interpretation of the bladder. 3rd ed. Philadelphia: Wolters Kluwer, 2017; 164-96.

59. Risio M, Coverlizza S, Lasaponara F, Vercesi E, Giaccone G. Inverted urothelial papilloma: a lesion with malignant potential. Eur Urol 1988; 14: 333-8.

60. Cox R, Epstein JI. Large nested variant of urothelial carcinoma: 23 cases mimicking von Brunn nests and inverted growth pattern of noninvasive papillary urothelial carcinoma. Am J Surg Pathol 2011; 35: 1337-42. 